\title{
Una historia de la Shigella, desde Jerjes a Saddam Hussein
}

\author{
WALTER LEDERMANN D.*
}

\section{A history of the Shigella, from Jerjes to Saddam Hussein}

La disentería constituye una entidad conocida desde muy antiguo. Por supuesto - ¡cómo no!- ya fue mencionada por Hipócrates medio milenio antes de Cristo. Compañera inseparable de la infantería en las largas marchas de la historia bélica, aparece en boca de Heródoto diezmando a las tropas que Jerjes dejara con Mardonio en Tesalia, luego de su desastrosa derrota en Salamina. "Y cuando no hallaban víveres algunos", cuenta en Urania, el octavo de los Nueve libros de la Historia, "contentábanse con la hierba que la tierra naturalmente les daba, con las cortezas quitadas a los árboles y con las hojas que iban cogiendo... que a todo los obligaba el hambre, sin que dejaran de comer cosa alguna que comerse pudiese $y$, de resultas de esto, iban acabando con el ejército la peste y la disentería que les sobrevino...". Y sigue: "A los que caían enfermos, dejábanlos en las ciudades por donde pasaban, mandándolas que tuvieran cuidado de curarlos y alimentarlos”... ¡Magnífica manera de perpetuar la epidemia en las ciudades devastadas! .

Muchos años más tarde, en el siglo de Augusto, el médico romano Aurelio Cornelio Celso, en el cuarto de sus Ocho libros de la Medicina, habla de "la enfermedad que los griegos llamaron disentería", describiendo como "interiormente los intestinos se ulceran y de ellos se desprende sangre, que se expulsa mezclada, bien con materias fecales y siempre líquidas, bien con una especie de mucosidades" "A veces -agrega- se escapa al mismo tiempo algo así como restos de carne, se sienten frecuentes deseos de ir a evacuar y dolor en el ano".

En la Edad Media se registra una gran epidemia en Bourdeaux, Francia, en el 1401, durante el curso de los enfrentamientos entre los bandos de Borgoña y de Orleans, que tuvo una letalidad superior a la procurada por las armas. Superado el brote, la bacteria causante permaneció al acecho, como si presintiera que estaba destinada a salvar al país de los apetitos ingleses. El 11 de agosto de 1415, Henry V desembarcó en Harfleur, sitiando esta plaza, que terminó por caer a mediados de septiembre, dando lugar a los inmortales versos de Shakespeare:

Otra vez en la brecha, amigos queridos, otra vez, O a cerrar la muralla con nuestros muertos ingleses.

La campaña de Henry V fue breve y se la recuerda, más por sus logros políticos, que poco duraron, por su glorioso triunfo en Azincourt. Los franceses, superiores en una proporción de veinte a uno, confiaban en tomar merecida venganza de su célebre derrota en Crecy el pasado siglo; en la noche anterior, seguros y jactanciosos, se jugaban a los dados el rescate que pagarían al día siguiente los prisioneros ingleses. El 25 de octubre, día de San Crispín, en un par de horas, Henry V obtuvo, al decir de Churchill, "la victoria más heroica que las armas inglesas han librado en tierra en toda su historia". Tras su victoria, Henry estuvo a un paso de reunir en su persona las coronas de Francia e Inglaterra, lo que se concretaría cuando muriese el Rey Carlos VI de Francia, pero la Shigella dijo otra cosa: " $L a$ fortuna, que le diera a Henry $V$ cuanto pudo soñar, no iba a arriesgar tan buena labor concediéndole larga vida: en la pleamar de su poder y su buena fortuna murió, a fines de 1422, de una enfermedad contraída en campaña, probablemen-

\footnotetext{
* Médico microbiólogo e infectólogo pediatra del Hospital Luis Calvo Mackenna.
} 
te disentería, contra la cual poco podía entonces la medicina"3.

Esta epidemia, que siguió a la hazaña de Azincourt, duró muchos años y diezmó no sólo los ejércitos en campaña, sino los campos destinados a procurarles los alimentos. Contaminadas las aguas vecinas a los campamentos, sin nociones de higiene y sin ninguna intuición acerca de la forma de contagio, la diseminación por extensas zonas de Francia era inevitable. Tras largos períodos de calma, la endemia se expresaba en súbitos brotes rurales, en relación a los frecuentes conflictos bélicos, que terminaban por llevar la Shigella a las ciudades, situación que se mantuvo a través de la Revolución y del Imperio, hasta tiempos muy recientes. Durante la primera guerra mundial, entre 1914 y 1918, la disentería se hizo presente todos los años en la estación cálida, especialmente los veranos de 1915 y 1918, golpeando selectivamente ciertas regiones, como la Argonne 4 .

No debe sorprender entonces que en Francia se descubriera el agente causal, aunque el crédito definitivo quedara luego en poder de un japonés. En 1888, Chantemesse y Widal describieron los caracteres del bacilo específico de la disentería y señalaron su acción patógena en animales, pero sus hallazgos no fueron consistentes ni sus publicaciones convincentes, debiendo contemplar impotentes como, diez años después, la publicación de Shiga le adjudicara a éste todos los créditos ${ }^{4}$.

El profesor Kiyoshi Shiga fue un sabio singular, que merece algunas líneas, empezando por aquella frase suya que mejor resume su tarea:

\section{Seguid el espíritu del mentor, no sus pasos.}

¡Bien vendría a muchos investigadores reflexionar sobre el sentido de estas palabras! Pero... ¿qué es un mentor? Mentor, destacado ciudadano de Itaca, tuvo la grave responsabilidad de educar a Telémaco, hijo del errante Ulises. El héroe, ocupado en el sitio de Troya y luego vagando veinte años por los mares, por culpa de sus hombres que sacrificaron algunas sagradas vacas del Sol, a cuya airada protesta respondió Zeus destrozando la nave aquea, no tuvo oportunidad de enseñar a su hijo y la difícil tarea recayó en su amigo Mentor. Este era también un gran guerrero: cuando Ulises arroja su disfraz de mendigo y se enfrenta a los numerosos pretendientes en la gran sala del palacio, acompañado tan sólo por el porquerizo Eumeo y Telémaco mismo, mientras el pastor Filetio guarda la puerta, la divina Atenea aparece a su lado en la figura de Mentor, cuya presencia pone espanto entre los enemigos 5 .
El mentor de Shiga fue Shibasaburo Kitasato, ayudante de Koch en Alemania, el Pasteur japonés, descubridor del Clostridium tetani y luego elaborador de la antitoxina. $\mathrm{Al}$ encontrarse en el Instituto de Enfermedades Infecciosas de Tokio, el maestro instó al discípulo a trabajar en la búsqueda de la etiología del sekiri, esto es, la disentería. Shiga se puso a la tarea y encontró un bacilo similar al tifoso en las deposiciones de 34 de 36 enfermos de disentería aguda, el cual aglutinaba por sueros obtenidos de los pacientes mismos, pero no por otros sueros, ya fuesen normales o patológicos.

Primero procedió Shiga a inocular cobayos, perrillos y gatitos, en los cuales provocó algunos desaguisados menores, pero no diarrea. Entonces se autoinoculó subcutáneamente, si bien con un cultivo muerto, acusando severas reacciones locales y generales, pero logrando a los diez días un suero capaz de aglutinar al bacilo disentérico. Con estos hallazgos, concluyó acertadamente que estaba en presencia de la bacteria causante de la enfermedad, publicando su descubrimiento en 1898, complementándolo con otras publicaciones sobre la materia en 1901, 1902 y $1908^{6}$.

Faltaba ahora, siguiendo las ideas de la época, en cada bacteria tenía su vacuna, desarrollar ésta. Con los conocimientos disponibles entonces, la cosa parecía muy simple, de modo que preparó un espeso cultivo, lo esterilizó por calor y obtuvo una clásica -y tóxica- vacuna a células enteras, que se autoinoculó sin vacilar. Sólo logró una reacción local tan considerable, que terminó en incisión quirúrgica para drenaje. Pero el hombre no se desalentó y siguió el espíritu del mentor, probando primero la inmunización pasiva con suero obtenido de animales y luego una vacuna oral, que estimó satisfactoria. Sin mayor trámite, en un tiempo en que los estudios controlados de campo eran desconocidos, la vacuna fue administrada a miles de japoneses. Pasarían muchos años, hasta 1936, hasta que el propio Shiga pusiera en tela de juicio sus resultados y enunciara que, quizás, pudieran ser más útiles la buenas prácticas de higiene pública que vacunas de dudosa eficacia?

Entretanto, el sabio se había casado con la señora Ichiko, en 1900, y comenzaba a reproducirse como las Shigella: tuvo 8 hijos. Se trasladó a Alemania y trabajó con el multifácetico Paul Ehrlich en la quimioterapia de la tripanosomiasis, pero volvió a su país con su mentor japonés en 1905, para terminar sus estudios sobre la disentería, que presentó triunfalmente en el Primer Congreso Asiático de Medicina Tropical, en Manila, $1906^{8}$. 
Los sabios son quisquillosos en todas partes del mundo y también en Japón. En 1914 el Emperador ordenó reestructurar el Instituto y Kitasato se sintió pasado a llevar, de manera que emigró y formó su propia institución. Shiga, contradiciendo su premisa, esta vez siguió los pasos del mentor y lo acompañó en la aventura, que consistió en la creación del Instituto Kitasato, donde encabezó una de los departamentos. Estuvo allí hasta 1920, pasando entonces a la Universidad Keio de Tokio, y más tarde a la colonia de Corea, como director del Hospital Nacional de Seul y luego Decano de la Facultad de Medicina, llegando a ser Presidente de esta Universidad de Seul en 1929. Volvió a Japón en 1931 para trabajar de nuevo con Kitasato, pero el maestro murió el mismo año, y Shiga siguió en solitario investigando en tuberculosis hasta 1945.

La Segunda Guerra Mundial fue un terrible golpe para Shiga. Su casa fue destruida por una bomba y debió retirarse y vivir en Sendai con su hijo Makoto; sus hijos Naoshi y Akira murieron a causa de la guerra, uno torpedeado en el mar cuando viajaba al funeral de su madre, y el otro de tuberculosis contraída en las trincheras chinas ${ }^{9}$.

Shiga falleció a los 85 años, el 25 de enero de 1957, ocasión en que The New York Times expresó que podría ser considerado uno de los cuatro o cinco bacteriólogos más eminentes en sus años más activos ${ }^{10}$. ¿No será mucho? Una docena de nombres se vienen a la mente antes que el suyo. Todavía, una última perla: cuando todos creíamos que su mentor había sido Kitasato, Shiga escribió una biografía en japonés de Paul Ehrlich, su "amigo y mentor". Dejémoslo ya y volvamos a nuestra bacteria.

Los descubrimientos en relación al poder patógeno del bacilo de Shiga habían, entretanto, continuado uno tras otro. En 1903, Conradi bañó placas de cultivo con solución salina, que luego filtró y concentró, demostrando que bastaba 0,1 $\mathrm{ml}$ para matar un conejo en 24 horas. El mismo año Rosenthal obtuvo la toxina de un caldo de cultivo, logrando los mismos resultados mortales al inocular sus conejos vía subcutánea, pero también anticuerpos protectores de los animales sobrevivientes. Por último, Sudmerson, Runge y O'Brien hicieron en 1924 una cuidadosa extracción y purificación de la toxina, determinando que la dosis letal para el ratón era 0,005 mg de toxina desecada, inyectada intravenosa ${ }^{11}$.

En 1919, tuvieron lugar los curiosos experimentos de Taylor con las moscas, a las cuales alimentaba con cultivos en leche del bacilo de Shiga, recuperando luego la bacteria en sus de- posiciones en 7 de 71 de los insectos. Examinaba las deposiciones cada doce horas, hasta que las moscas morían, lo que ocurría a veces antes de las veinticuatro. En una segunda etapa, Taylor cazó 1.670 moscas en las salas, cocinas y letrinas de dos hospitales, de las cuales examinó 1.500 sin encontrar el bacilo. Durante el brote estival de disentería, Taylor examinó otras 1.240 moscas, recuperando apenas un bacilo similar al disentérico, pero inaglutinable. Por último, aprovechando un período en que su hospital estaba lleno de moscas y de disentéricos, capturó otras 330 y logró aislar un bacilo de Shiga de una mosca atrapada en la cocina sorbiendo un flan de vainilla. El sagaz investigador concluyó que las moscas trasmitían la enfermedad, pero sus resultados se estimaron muy poco convincentes, si bien se hicieron algunas recomendaciones para descontaminar las heces de los disentéricos con ácido carbólico ${ }^{12}$.

En ese mismo año, Dudgeon y Urquart estudiaron in vivo la acción de la toxina, inoculando hasta 7.500 millones de bacilos en el lumen intestinal de conejos, matando sólo a uno de ellos, en cuyo intestino no encontraron úlceras, pero sí una manifiesta reacción inflamatoria. En cambio, al inocular estos cultivos por vía venosa, todos morían antes de los tres días por acción puramente tóxica. En cuanto a las vacunas, luego de la autoinoculación de Shiga, los investigadores fueron muy cautos, determinando que ya 200 millones de bacilos causaban una reacción intolerable $^{13}$. Sin embargo, en 1921 Vincent se atrevió a superar esa concentración y vacunó 2.175 personas con 500 a 750 millones de bacilos, con el fin de abortar un brote epidémico, y entre sus vacunados sólo hubo 33 casos de disentería, siendo las tasas de ataque de 16 por mil entre los vacunados y de 228 por mil entre los no vacuna$\operatorname{dos}^{14}$. Un resultado más espectacular había obtenido Shiga en 1900, al vacunar a 10.000 japoneses con una mezcla de bacilos y antisuero, bajando la mortalidad, pero no el número de casos, aunque en la villa de Koai bajó la incidencia de 28 casos por mes a cero, bellos resultados que los investigadores ingleses no pudieron reeditar, cayendo la vacuna de Shiga en descrédito en Occidente. En 1919, Olitsky logró reducir las reacciones locales preparando su vacuna en aceite de almendras dulces y, en los años siguientes, numerosos investigadores ensayaron vacunas orales según el método de Besredka, con bacterias sensibilizadas a la bilis. Pese a algunos éxitos en pequeños brotes, en estudios comparativos que apenas superaban los mil vacunados, la vacuna oral fue un fracaso ${ }^{15}$. El más importante se realizó 
en India, en prisiones de Bengala y Madrás, procedimiento que hubiera hoy horrorizado a cualquier comité de ética, con una dosis de 100.000 millones de bacilos disentéricos por vía oral. Se utilizaron dos vacunas, una bilivacunaShiga, preparada por La Biothérapie, de Francia, y una emulsión estéril de bacilos de Shiga y de Flexner, del Laboratory of Tropical Medicine, Calcutta, con cepas locales. Se vacunaron en total 1.136 prisioneros, contra 5.569 controles no vacunados, con porcentajes de incidencia de disentería de 2,16-2,88 para los supuestamente inmunizados y de 4,46 y 5,2 para los controles ${ }^{11}$.

Los franceses no se quedaban atrás en la lucha contra el bacilo del japonés: Vaillard y Dopter, asombrados por el gran aflujo leucocitario en la mucosa intestinal, acuñaron el término "leucocitorrea", convirtiéndose en los padres de los leucocitos fecales, examen hoy muy difundi$\mathrm{do}^{16}$, en tanto que Broleman desarrolló una intradermo-reacción diagnóstica con la toxina, que pretendió inútilmente equiparar a la Shick para la difteria ${ }^{4}$. Pero el más famoso investigador fue D'Herelle, autor de la fagoterapia, esto es, la administración de virus que destruyesen los bacilos. El sabio nunca vio los bacteriófagos, limitándose a filtrar las deposiciones de los enfermos y a lisar con este filtrado cultivos rebosantes de bacilos de Shiga. Luego aplicó su filtrado a los enfermos, estableciendo una serie de reglas y principios de administración, pero su tratamiento no fue convincente. Años más tarde, Jan Kapisek logró espectaculares resultados en el campo de concentración de Terezin, repleto de prisioneros aquejados de disentería que los alemanes habían dejado allí. Las pruebas de laboratorio sugerían, sin embargo, que el agente causal era una cepa atóxica de bacilo de Flexner y no un auténtico Shiga, "pero el curso de la enfermedad en esos detenidos, esposados, subalimentados y torturados era hipertóxico". Kapisek dio a cada enfermo $20 \mathrm{ml}$ tres veces al día, con té o café, luego de alcanizarles el estómago; si vomitaban, se les administraba $150 \mathrm{ml}$ vía rectal, con una sonda Nelaton. De acuerdo a su gravedad, los enfermos mejoraron entre uno y tres días, cayendo la mortalidad del 34 al 5\%, en tanto que el 5\% de recidivas mejoró con la vía rectal. En total, Kapisek trató a tres mil enfermos graves con 913 litros de bacteriófagos ${ }^{17}$.

Las sulfas terminaron con las bilivacunas y sueros terapéuticos, con los bacteriófagos y las antitoxinas: a la matin, une pilule d'extrait biliaire, et un quart d'heure après, une pastillevaccin melangée avec de la lactose $e^{4,18,19}$. Luego vendrían la estreptomicina, el cloranfenicol, la ampicilina, de nuevo el cloranfenicol y ahora las quinolonas. Pero los tiempos no cambian tanto, el hombre sigue yendo a la guerra, y el bacilo de Shiga acompañó recientemente a las tropas norteamericanas en Irak, con resultados previsibles: de acuerdo a una encuesta, el $57 \%$ de las tropas tuvo diarrea y un $20 \%$ estuvo temporalmente inhabilitado para el servicio. En los meses iniciales de agosto y septiembre de 1990, se presentaban 50 a 100 casos de diarrea por mil hombres por semana, primero acuosa y luego sanguinolenta. En un estudio etiológico de 432 casos, el primer lugar fue para el género Shigella, con un $25,2 \%$ de las diarreas, aventajando al 19,7\% de Escherichia, aunque el bacilo de Shiga apenas afectó a 4 soldados, con un modesto $0,9 \%$. Pero estuvo ahí, una vez más, como en los tiempos de Heródoto $^{20}$.

En un viejo tratado de 1896 encontramos esta pesimista declaración de Charles Viry, Médico Principal de $1^{\text {a }}$ clase, Director del Servicio de Salud del $2^{\circ}$ Cuerpo de la Armada francesa: $E l$ soldado, poco cuidadoso de su salud y obedeciendo a sus instintos, desechará siempre el agua de buena calidad, recalentada por su permanencia en los reservorios, y buscará en el cuartel agua de calidad dudosa, en principio reservada a la limpieza, pero que estará más fresca. En vano se ensayará protegerlo contra su imprudencia, inscribiendo, como está prescrito desde hace tiempo, encima de las tomas de agua sospechosas: Eau non potable, interdite, dangereuse. ;Esas indicaciones no han jamás impedido el nacimiento de más de una epidemia de disentería o de fiebre tifoidea! ${ }^{21}$.

De Jerjes a Saddam Hussein, ninguna Shigella nueva bajo el sol.

\section{Bibliografía}

1.- Heródoto. Los 9 libros de la historia. Editorial Iberia, Barcelona 1968; II: 272.

2 .- Celso A C. Los ocho libros de medicina. Editorial Iberia, Barcelona 1968; I: 204-6.

3.- Churchill W. Historia de Inglaterra y de los pueblos de habla inglesa. Peuser, Buenos Aires 1958; I: 330-9.

4.- Le Bourdelles B. La dysenterie bacillaire. Maladies Infectieuses, Paris 1935; 8026: 1.

5.- Homero. La odisea. Versión de Fernando Gutiérrez. Editorial Maucci, S.L.Barcelona 1962; pp: 276-81 y 465-80.

6.- Shiga K. The trend of prevention, therapy, and epidemiology of dysentery since the discovery of its causative organism. N Engl J Med 1936; 215: 120511

7.- Shiga K. Observations on the epidemiology of dysentery in Japan. Philip J Sci 1906; 1 : 485-500.

8.- Shiga K. Über dysenteric Bacillus. Z Hyg InfektKr 
1908; 60: 75-81.

9.- Trofa A, Ueno-Olsen H,Oiwa R, Yoshikawa M. Doctor Kiyoshi Shiga, discoverer of the dysentery bacillus. Clin Infect Dis 1999; 29 (5): 1303-06.

10.- Obituary. The New York Times 1957 (Jan 26th); 19: 6.

11.- Dudgeon L S. B. dysenteriae (Shiga). In: A system of bacteriology in relation to medicine. His Majesty Stationery Office, London 1949; IV: 184-220.

12.- Taylor J F. Spread of Shiga bacilli by flies. Spec Rep Ser Med Res Comm 1919; 40: 20-5.

13.- Dudgeon y Urquart. Recently isolated cultures of Shiga bacillus injected into the lumen of intestine in rabbits.. Spec Rep Ser Comm 1919; 40: 16-9.

14.- Vincent H. Résultats de la vaccination antidysentérique. CR Soc Biol, Paris 1921; p: 965-72.

15.- Olitsky P K. Shiga vaccine with a suspension of dysenty bacilli in almond oil. J Exp Med 1918; 28: $69-75$.

16.- Vaillard L, Dopter C. Inoculation chez le lapin avec le bacille de Shiga. Ann Inst Pasteur 1903; 17: 463-9.

17.- Kapisek J. Contribution à l'emploi du bacteriophage dans le traitement de la dysenterie bacillaire. Presse Méd 1947 (Juin 21); 422-3.

18.- Hamilton Farley, N Progres dans le traitement des maladies tropicales. Practitioner 1947; 159: 269.

19.- Weil A J. La dysenterie bacillaire. Rev Imunologie 1946; 10: 305-11.

20.- Hyams K C, Bourgeois A L, Merrell B R et al. Diarrheal disease during Operation Desert Shield. N Engl J Med 1991; 325 (20): 1423-8.

21.- Viry Ch. Principes d'hygiene militaire. L. Bataille et Cie. Editeurs, Ancienne Maison Delahaye, Paris 1896; p: 336 . 